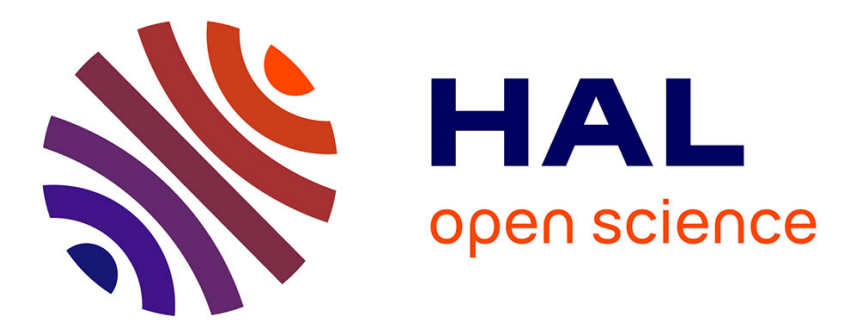

\title{
Study of Thermal and Kinematic Phenomena Associated with Quasi-static Deformation and Damage Process of some Concretes
}

\author{
Vincent Huon, Bruno Cousin, Olivier Maisonneuve
}

\section{- To cite this version:}

Vincent Huon, Bruno Cousin, Olivier Maisonneuve. Study of Thermal and Kinematic Phenomena Associated with Quasi-static Deformation and Damage Process of some Concretes. Michel Frémond; Franco Maceri. Novel Approaches in Civil Engineering, Springer, pp.187-201, 2004, 978-3-540-41836-8. 10.1007/978-3-540-45287-4_14. hal-03342781

\section{HAL Id: hal-03342781 \\ https://hal.science/hal-03342781}

Submitted on 14 Sep 2021

HAL is a multi-disciplinary open access archive for the deposit and dissemination of scientific research documents, whether they are published or not. The documents may come from teaching and research institutions in France or abroad, or from public or private research centers.
L'archive ouverte pluridisciplinaire HAL, est destinée au dépôt et à la diffusion de documents scientifiques de niveau recherche, publiés ou non, émanant des établissements d'enseignement et de recherche français ou étrangers, des laboratoires publics ou privés. 


\section{Study of Thermal and Kinematic Phenomena}

\section{Associated with Quasi-static Deformation and Damage Process of some Concretes}

Vincent Huon, Bruno Cousin, Olivier Maisonneuve

Laboratoire de Mécanique et Génie Civil,

cc 048, Université Montpellier II,

F-34095 Montpellier Cedex 5, France

\section{Introduction}

Since many years, the use of optical methods for studying behaviour of materials has made great strides. These techniques give information to improve macroscopic behaviour laws and allow observing initiation and propagation of localization phenomena. In the field of civil engineering materials and structures, optical measurements of the displacement field are more and more used (stereophotogrammetry [3], for example). On the other hand, infrared thermography is not very used to study the behaviour of concretes. For dynamical solicitation, it is common to refer of M.P Luong's works [6].

This work shows what we are able to obtain in the framework of quasistatic mechanical solicitations imposed on concretes by using digital speckle images correlation in whiting light mode and infrared thermography. In this paper, we study both Reactive Powder Concrete (RPC) and damaged freeze /thaw plain concrete.

\section{Experimental arrangement and studied materials}

\subsection{Experimental device}

The experimental set-up uses a tension-compression testing machine (either a DARTEC $\pm 100 \mathrm{kN}$ or a MFL UED40 $400 \mathrm{kN}$ ) coupled with an infrared camera or a CCD video camera. The thermal measures are realized either with a camera AGEMA $880 \mathrm{sw}\left(\mathrm{NETD}=0.2^{\circ} \mathrm{C}\right.$ at $\left.30^{\circ} \mathrm{C}\right)$ or with a camera CEDIP JADE $3 \mathrm{mw}\left(\mathrm{NETD}=0.025^{\circ} \mathrm{C}\right.$ at $\left.35^{\circ} \mathrm{C}\right)$. An image processing is performed in order to filter noisy data provided by the camera.

For speckle images, we used a CCD video camera PANASONIC WC-CP410. The method of measure of the displacement is based on digital images correlation techniques. The differentiation of the displacement field is done by a local approximation method [10]. 


\subsection{Studied materials}

RPC are ultra-high-strength concretes reinforced with steel fibres [9]. The mechanical properties are a compressive strength of $200 \mathrm{MPa}$, a flexural strength of $35 \mathrm{MPa}$ and Young modulus around $65 \mathrm{GPa}$.

The damaged freeze/thaw concrete is a plain concrete with a classic mixture: a granular class of $0-4 \mathrm{~mm}$ with water/cement and cement/sand ratios of 0.5 and 0.3 , respectively. The specimens have been aged by rapid freeze/thaw cycles at the Norwegian Building Research Institute [3]. The procedure was the ASTM C666. Fourteen cycles were applied with a cooling rate approximately $12^{\circ} \mathrm{C} / \mathrm{h}$ in the limit $+5 /-18^{\circ} \mathrm{C}$.

\section{Strain localization phenomena occurring during tensile test on RPC 200 samples}

The sample is shown in the figure 1a. The grip setting of the specimen, used to assign the tensile loading, is described in the figure 1b. The experimental results are obtained during monotone tensile tests performed at constant cross-head velocity $\left(\mathrm{V}_{C H}=10^{-2} \mathrm{~mm} \cdot \mathrm{s}^{-1}\right)$.
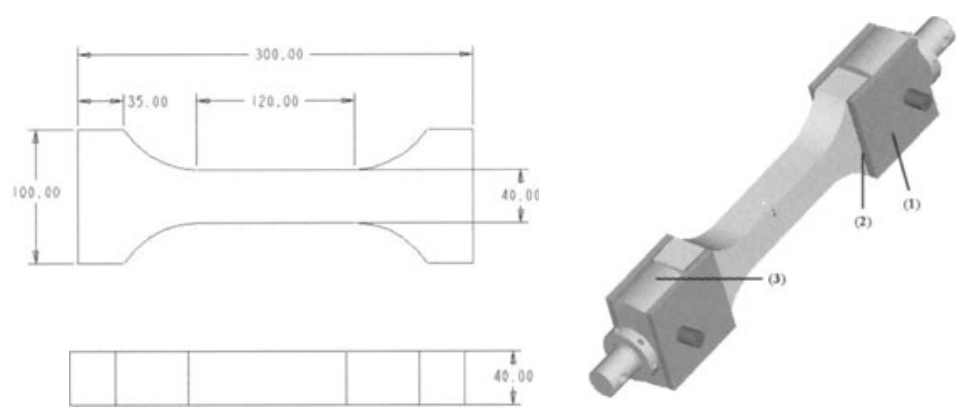

Fig. 1. a Direct tensile specimen - b Grip system

\subsection{Loading/unloading tensile tests}

To represent the entire test in the same figure, we choose to plot the axial distribution of the tension component of the strain tensor. Figure 2 presents the tension component of the strain tensor of the points located along the longitudinal axis (i.e. $\mathrm{x}_{1}$ axis) for a given loading state (black curve) as a function of time (image number). In a first observation, during the first loading cycle, the RPC behaviour exhibits two stages. The first, until image 45, is due to the elastic behaviour of material with slight homogeneous strain. 


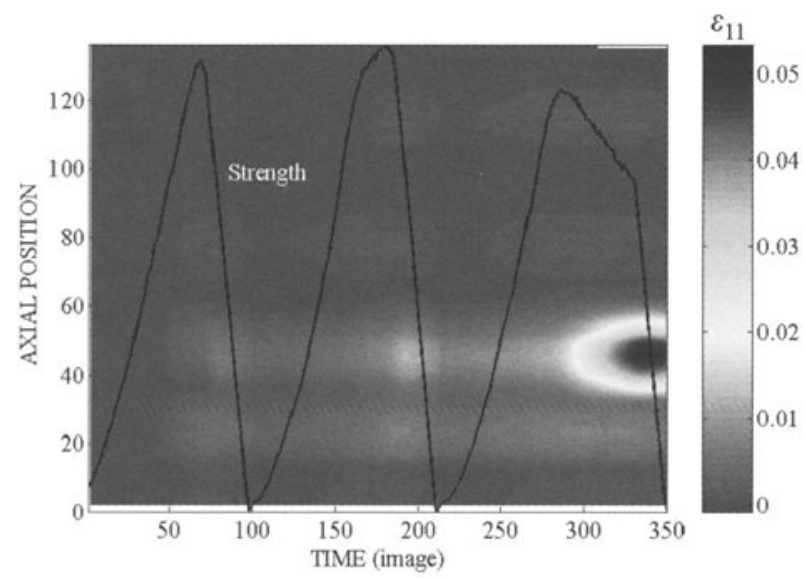

Fig. 2. Lengthwise profiles of the longitudinal component of the strain tensor rate $\left(F_{\max }=26 k N\right.$, acquisition $\left.1 \mathrm{i} / \mathrm{s}\right)$
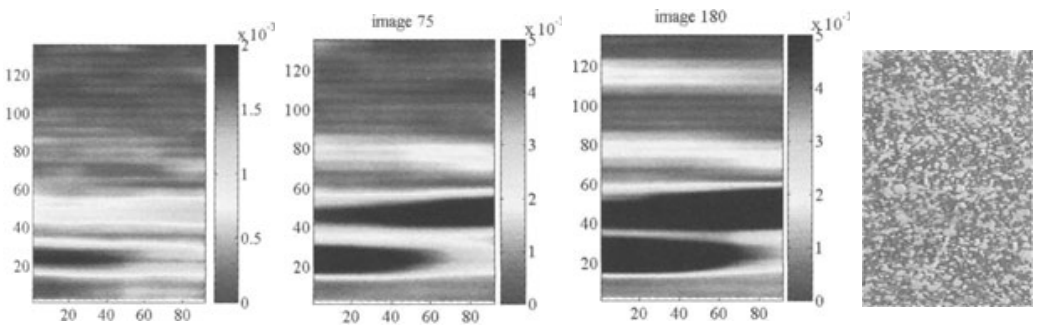

Fig. 3. Longitudinal strain field at the image

a 45 - b 75 - c 180 - d image 45 of the sample

In the second stage, many areas of strain localization ("multi localization") appear which may lead to the development of macro cracks.

Although we observe two strain localization areas, on figure $3 \mathrm{a}$, no crack is visible on the sample. At this time, it seems that the macro crack will appear in the localization area A (fig. 3a). In fact, this is the area B that leads to the creation of macro crack (fig. 2).

During the loading, we observe (fig. 2) that residual strain are more or less important depending on the level of localization. Contrary to the area $\mathrm{C}$, the areas $\mathrm{A}$ and $\mathrm{B}$ are the seats of residual strain.

The second loading cycle shows that the localization areas are irreversible (permanent). From the outset of loading, we observe an accumulation of deformation in the areas already identified. These areas are due to a state of damage more important than in the other parts of the sample. This second cycle also illustrates the essential role of the fibres in the transmission of stress 
around the neighbourhood of the damaged zones, leading to the apparition of a new damaged area $\mathrm{D}$, for example.

\subsection{Tensile-compressive tests}

An outstanding characteristic of the concrete behaviour is the unilateral effect. How is it for a RPC?

Experimental results The figure 4 gives the evolution of the longitudinal component of the strain tensor for a given loading state (black curve).

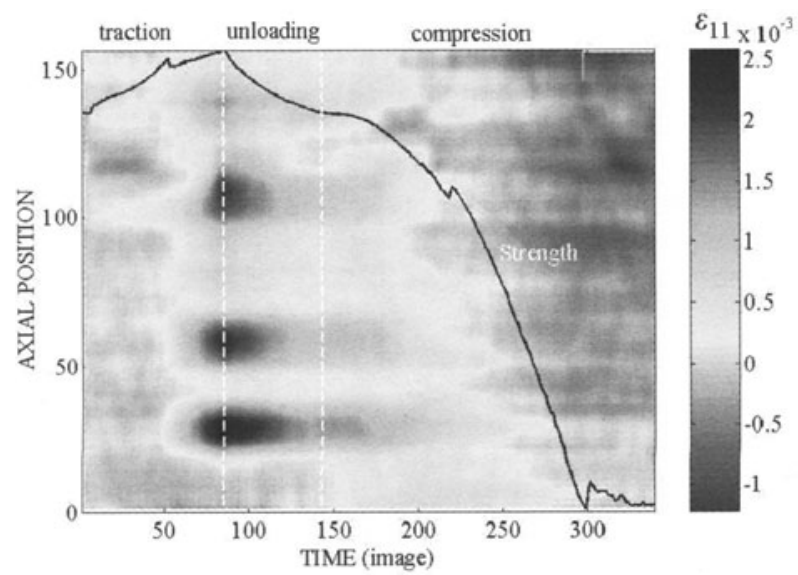

Fig. 4. Lengthwise profiles of the longitudinal component of the strain tensor rate $\left(F_{\max }=9.5 \mathrm{kN}\right.$ in traction and $-60 \mathrm{kN}$ in compression, acquisition $\left.1 \mathrm{i} / \mathrm{s}\right)$

We distinguish on this figure three phases according to the loading state: (1) the traction which leads to "multilocalisation" of the strain; (2) the unloading associated with residual strain distributed on the entire sample but more important where there were strain localizations; (3) during the compression the residual strains progressively come out. At the end of the compression $(\sigma=40 \mathrm{MPa})$ we have a quasi-homogeneous strain state.

Stress-strain relationship analysis For a plain concrete, a compressive loading applied to the damaged materials induces a recovering of the stiffness (unilateral character). Let us consider the case of RPC?

With the kinematic measures, we can plot the stress-strain diagram for a gauge length of $30 \mathrm{~mm}$ at the centre of the sample.

On figure $5 \mathrm{a}$, we observe damage during the traction and a recovering of the 
stiffness at the beginning of the compressive loading. We can see a difference of the stiffness between an undamaged sample and a damaged sample in the figure 5b. It seems there is not a total recovering of stiffness due to the fibres that interfere with crack closure.
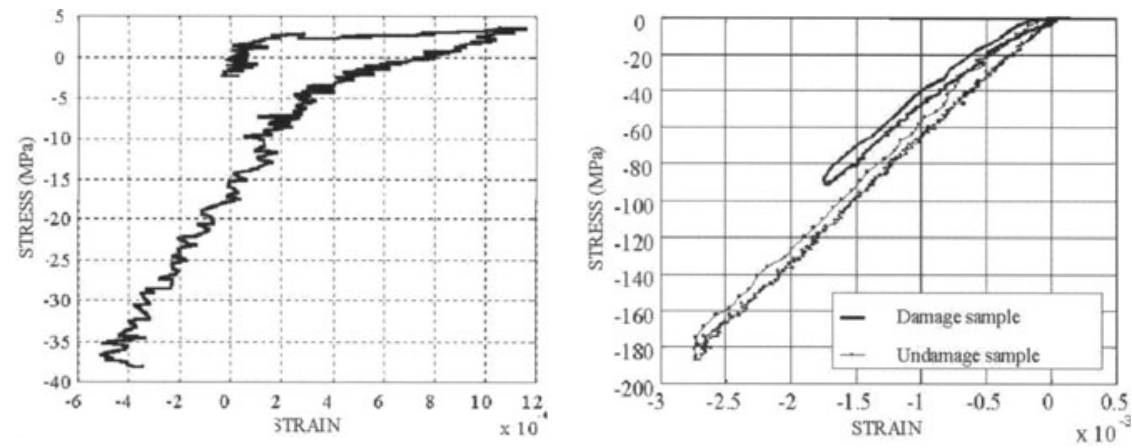

Fig. 5. Stress-strain relationship of a RPC sample - a Undamaged solicited in traction-compression - $\mathbf{b}$ Undamaged and damaged solicited in compression

\section{Thermal effects associated to deformation of RPC200}

Observations by the infrared thermography have been achieved on the undamaged sample during three loading/unloading cycles in compression. The experimental results are obtained during test performed at constant crosshead velocity $\left(\mathrm{V}_{C H}=5 \cdot 10^{-2} \mathrm{~mm} \cdot \mathrm{s}^{-1}\right)$.

\subsection{Experimental results}

The evolution of the temperature variation of the median axis of the sample versus time is represented figure 6 . In overprinting, the strength evolution is plotted (white curve).

During the test, the temperature is uniform in the sample and we observe positive evolution of the temperature associated with the loading evolution. The amplitude of the temperature variation is around $0.3^{\circ} \mathrm{C}$ for a maximal stress of $160 \mathrm{MPa}$. At first sight, this effect could be attributed to a thermoelastic coupling that we would like study.

\subsection{Valuation of the thermoelastic coupling}

We start our analysis with the linearized heat conduction. The second member only includes the thermoelastic coupling as heat source term. The linearization is justified since the thermal effect is negligible. 




Fig. 6. Lengthwise profiles of temperature variation for RPC200 solicited in compression $\left(F_{\max }=250 \mathrm{kN}(160 \mathrm{MPa})\right.$, acquisition $\left.6.25 \mathrm{i} / \mathrm{s}\right)$

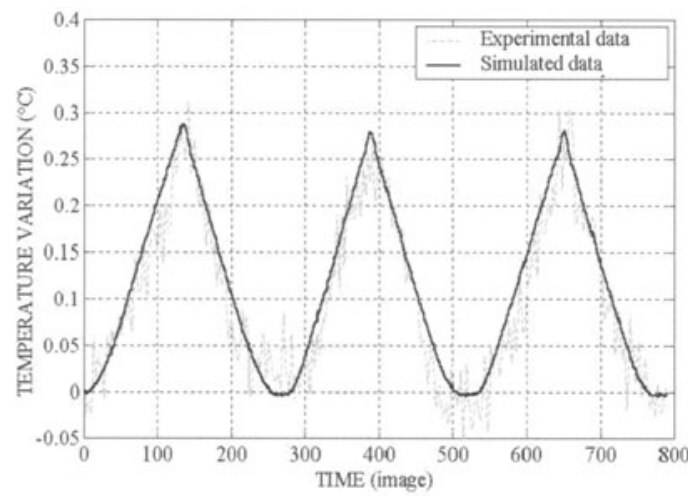

Fig. 7. Comparison simulation-experiment

The experimental observations (temperature variation in phase with the loading) and the thermal features of the material (low conduction) enable us to do the quasi-adiabatic working hypothesis during the test. After the corresponding simplification, we can write:

$$
\rho C \frac{\partial \theta}{\partial t}=-\left(\theta+T_{0}\right) E \alpha \dot{\epsilon}
$$

where $\rho, \mathrm{E}$ et $\ddot{\epsilon}$ have the usual significance and $\mathrm{C}$ and $\alpha$ denote respectively the specific heat capacity and the isotropic dilatation coefficient. While integrating with the initial condition $\theta=0$ at $\mathrm{t}=0, \theta$ being always little opposite $T_{0}$, we get: 


$$
\theta=-\frac{T_{0} \alpha \sigma}{\rho C}
$$

where $\sigma$ is the stress in the material at the considered moment.

Figure 7, we note that simulation results are consistent with experimental $\theta$ evolution with $\mathrm{T}_{0}=298 \mathrm{~K}, \rho=2,5 \cdot 10^{3} \mathrm{~kg} \cdot \mathrm{m}^{-3}, \mathrm{C}=838 \mathrm{~J} \cdot \mathrm{kg}^{-1} \cdot \mathrm{K}^{-1}[4]$ and $\alpha=12.10^{-6} \mathrm{~K}^{-1}$, reference value given for concrete with silica granular (BPEL 91). It confirms the interpretation given in $\S 4.2$.

\section{Compressive loading tests on freeze/thaw damaged plain concrete}

Three freeze/thaw damaged samples have been subjected to a compressive test of 20 loading-unloading cycles. We have previously checked the damaged status with a preliminary loading-unloading compressive test. The experimental results are obtained during a test performed at constant cross-head velocity $\left(\mathrm{V}_{C H}=5 \cdot 10^{-2} \mathrm{~mm} \cdot \mathrm{s}^{-1}\right)$. The strength evolution is quasi-identical for the three samples.

The thermal effects are studied with the camera CEDIP. For reasons of a storage capacity, we only made several shots, 3 or 4 , covering over 3 or 5 loading cycles.

\subsection{Experimental results}

They are displayed for the sample 1563F6 (the more damaged). The evolution of the temperature variation of the median axis of the sample during the test is represented figure 8. In overprinting, the strength evolution is plotted (white curve).

We observe two phenomena corresponding, the first, to the temperature variation in phase with the loading cycles and, the second, to a progressive warming-up of the sample during the test. The same observations (different quantitatively) have been made with the sample $1563 \mathrm{~F} 2$ and $1563 \mathrm{~F} 10$ (the less damage).The first phenomenon has already been identified as thermoelastic effect (see §4-RPC). In the following, we will focus on the analysis of the second phenomenon.

\subsection{Study of the progressive warming-up}

Figure 9, we compare the evolution of the temperature variation of 3 points for each sample, during the test. The most important temperature variations are observed on the previously identified sample as the most damage. To operate the results appropriately, it is necessary to quantify what could be 
due to the drift of the camera and of the ambient temperature. A sample has been filmed without any solicitation during a time equivalent to the timetest. The drift (positive) remains lower than $0.07^{\circ} \mathrm{C}$. There is a small impact of camera-environment drift in the observed warming-up.

Consequently, the evolution of the temperature map of the sample $1563 \mathrm{~F} 10$ can be allocated to the phenomenon of drift. On the other hand, it is not the same way for the samples $1563 \mathrm{~F} 2$ and $1563 \mathrm{~F} 6$. The increase of temperature observed at the end of the test (about $0.3^{\circ} \mathrm{C}$ ) are much higher than what has been observed for the drift. The differences between the sample $1563 \mathrm{~F} 2$ and $1563 \mathrm{~F} 6$, on the one hand, and the sample $1563 \mathrm{~F} 10$, on the other hand, must be related to the states of different damage induced by the freeze/thaw cycles. We can attribute this progressive warming-up to dissipative phenomena associated with the state of damage of the sample. Besides, we note (fig.8 and fig.9) a non-homogeneous warming-up along the sample. Unless there was a non-uniform drift of the camera in the space that we did not study, this heterogeneity of temperature could be associated with heterogeneity of the state of damage.

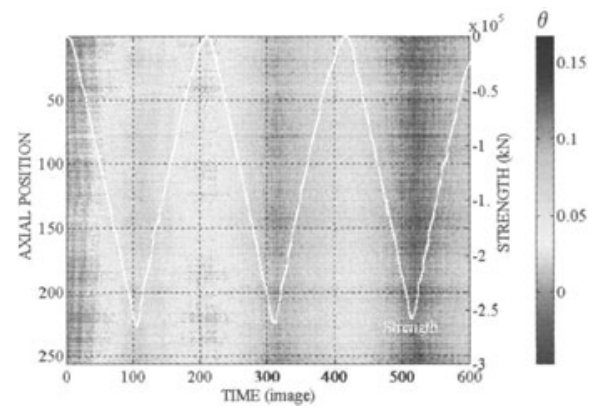

a cycle 1,2 and 3

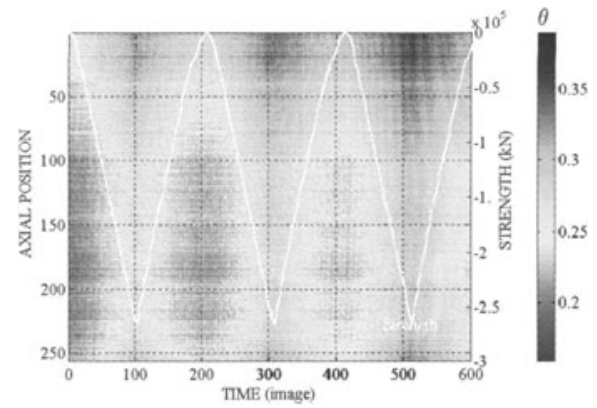

c cycle 12,13 and 14



b cycle 6,7 and 8

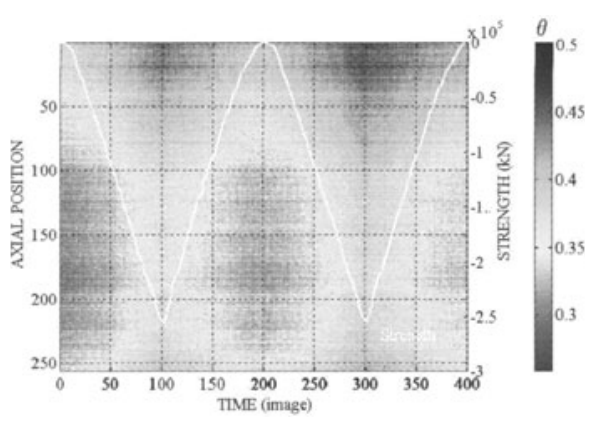

d cycle 19 and 20

Fig. 8. Sample 1563F6, lengthwise profiles of the temperature variation (20 loading/unloading cycles, $\left.F_{\max }=265 k N(35 \mathrm{MPa})\right)$ 

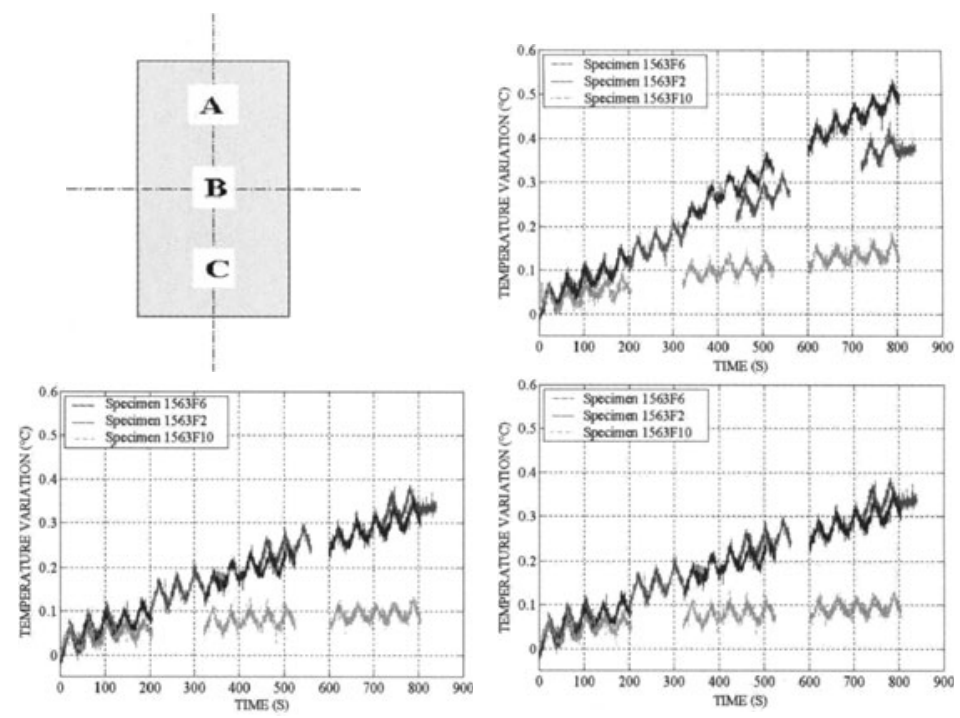

Fig. 9. Comparison of the temperature variation

\section{Modelling of the damage thermoelastic behaviour of a plain concrete}

To take into account thermal phenomena associated with the deformation of concrete, which damage it, we propose to expand the M. Fremond and B. Nedjar's model [8]. In the modelling, the temperature variable is taken into account through thermal phenomena associated with thermal dilatation.

\subsection{Free energy and pseudo-potential of dissipation}

We are led to choose the free energy, $\psi$, and the pseudo-potential of dissipation $\phi$ as:

$$
\begin{aligned}
& \Psi=\beta_{t}\left[\frac{1}{2}\left(2 \mu \operatorname{tr}\left[\epsilon_{t} . \epsilon_{t}\right]+\lambda\left(\left\langle\operatorname{tr} \epsilon_{t}\right\rangle^{+}\right)^{2}\right)-(3 \lambda+2 \mu) \alpha \operatorname{tr} \epsilon_{t}\right]+ \\
& \beta_{c}\left[\frac{1}{2}\left(2 \mu \operatorname{tr}\left[\epsilon_{c} . \epsilon_{c}\right]+\lambda\left(\left\langle\operatorname{tr} \epsilon_{c}\right\rangle^{-}\right)^{2}\right)+(3 \lambda+2 \mu) \alpha \operatorname{tr} \epsilon_{c}\right]+ \\
& W_{t}\left(1-\beta_{t}\right)+W_{c}\left(1-\beta_{c}\right)+\frac{k}{2}\left[\left(\operatorname{grad} \beta_{t}\right)^{2}+\left(\operatorname{grad} \beta_{c}\right)^{2}\right]-\frac{\rho C}{2 T_{0}} \theta^{2}+I_{c}\left(\beta_{t}, \beta_{c}\right) \\
& \Phi=\frac{1}{2}\left\{c_{t} \dot{\beta}_{t}^{2}+c_{c} \dot{\beta}_{c}^{2}\right\}-\frac{1}{2} \dot{\beta}_{t}\left(\frac{1-\beta_{t}}{1-M_{t} \beta_{t}}\right)\left[2 \mu t r\left[\epsilon_{t} \cdot \epsilon_{t}\right]+\lambda\left(\left\langle\operatorname{tr} \epsilon_{t}\right\rangle^{+}\right)^{2}\right]- \\
& \frac{1}{2} \dot{\beta}_{c}\left(\frac{1-\beta_{c}}{1-M_{c} \beta_{c}}\right)\left[2 \mu \operatorname{tr}\left[\epsilon_{c} \cdot \epsilon_{c}\right]+\lambda\left(\left\langle\operatorname{tr} \epsilon_{c}\right\rangle^{-}\right)^{2}\right]+I_{-}\left(\dot{\beta}_{t}, \dot{\beta}_{c}\right)
\end{aligned}
$$

With the notations:

$\beta_{t}$ and $\beta_{c}$ are the damage quantity respectively in tension and compression $(\beta=1$, undamaged material and $\beta=0$, complete damaged material); 
- the strain tensor is decomposed as: $\epsilon=\epsilon_{t}-\epsilon_{c}$, such as in traction $\epsilon=$ $\epsilon_{t}$ and in compression $\epsilon=-\epsilon_{c}$;

- $\quad \mathrm{W}_{t}$ and $\mathrm{W}_{c}$ are the initial thresholds respectively in traction and compression;

- $\quad \mathrm{M}_{t}$ and $\mathrm{M}_{c}$ are the factor of displacement of the thresholds $\mathrm{W}_{t}$ and $\mathrm{W}_{c}$; - $\quad \mathrm{K}$ measures the influence of the damage at a material point on the damage of its neighbourhood;

- $\quad c_{t}$ and $c_{c}$ are the viscosity parameters of damage;

- $\quad I_{C}$ and $I_{-}$are respectively the indicator functions of the triangle $C$ and of the set $]-\infty, 0] \times]-\infty, 0]$.

\subsection{Constitutive laws}

With these choices, the constitutive laws are:

$$
\begin{array}{r}
\sigma^{r}=\frac{\partial \Psi}{\partial \epsilon} \quad, B_{i}^{r} \in \frac{\partial \Psi}{\partial \beta_{i}} \quad, H_{i}^{r}=\frac{\partial \Psi}{\partial \operatorname{grad} \beta_{i}} \text {, with } i \in\{t, c\} . \text { We obtain: } \\
\sigma^{r}=-\beta_{c}\left(2 \mu \epsilon_{c}+\lambda\left(\left\langle\operatorname{tr} \epsilon_{c}\right\rangle^{-}\right) I d+(3 \lambda+2 \mu) \alpha \theta I d\right) \\
+\beta_{t}\left(2 \mu \epsilon_{t}+\lambda\left(\left\langle\operatorname{tr} \epsilon_{t}\right\rangle^{+}\right) I d-(3 \lambda+2 \mu) \alpha \theta I d\right)
\end{array}
$$

$$
B_{i}^{r} \in \frac{1}{2}\left(2 \mu t r\left[\epsilon_{i} . \epsilon_{i}\right]+\lambda\left(\left\langle\operatorname{tr} \epsilon_{i}\right\rangle^{s g n(\eta)}\right)^{2}\right)+\eta(3 \lambda+2 \mu) \alpha \theta t r \epsilon_{i}-W_{i}+\partial I_{c}\left(\beta_{i}\right)
$$

with $\eta=1$ if $\epsilon_{i}=\epsilon_{t}, \eta=-1$ if $\epsilon_{i}=\epsilon_{c}$. We let $\mathrm{H}_{c}=\mathrm{H}_{c}{ }^{r}+\mathrm{H}_{c}{ }^{i r}, \mathrm{H}_{t}=\mathrm{H}_{t}{ }^{r}+$ $\mathrm{H}_{t}{ }^{i r}, \mathrm{~B}_{c}=\mathrm{B}_{c}{ }^{r}+\mathrm{B}_{c}{ }^{i r}$ et $\mathrm{B}_{t}=\mathrm{B}_{t}^{r}+\mathrm{B}_{t}{ }^{i r}$, which in addition $\sigma=\sigma^{r}+\sigma^{i r}$, according to take into account in the power of the internal forces associated with damage and its gradient.

\subsection{Equations of damage evolution}

Like [8], the principle of virtual power is rewritten to take into account the power of the internal forces associated with microscopic motions.

$$
\begin{aligned}
& \rightarrow c_{i} \dot{\beta}_{i}-k \Delta \beta_{i}+\partial I_{-}\left(\dot{\beta}_{i}\right)+\partial I_{c}\left(\beta_{i}\right) \\
& \ni-\frac{1}{2}\left(1-\frac{1-\beta_{i}}{1-M_{i} \beta_{i}}\right)\left(2 \mu \operatorname{tr}\left[\epsilon_{i} . \epsilon_{i}\right]+\lambda\left(\left\langle\operatorname{tr} \epsilon_{i}\right\rangle^{\operatorname{sgn}(\eta)}\right)^{2}\right)+ \\
& W_{i}+\eta(3 \lambda+2 \mu) \alpha \theta t r \epsilon_{i} \quad \text { in } \Omega \\
& \rightarrow \quad k \frac{\partial \beta_{i}}{\partial n}=0 \quad \text { on } \partial \Omega
\end{aligned}
$$

\subsection{Heat conduction equation}

While adopting the assumptions leading to the classic form of the heat conduction equation: 


$$
\rho C \dot{T}-r+\operatorname{divq}=D_{1}+\rho T \frac{\partial^{2} \psi_{1}}{\partial T \partial \alpha_{k}}: \dot{\alpha}_{k}=w_{c h} \quad(k=1, \ldots, n)
$$

We obtain after linearisation:

$$
\rho C\left(\frac{\partial \theta}{\partial t}+\frac{\theta}{\tau_{t h}}\right)=w_{c h}
$$

where the $\alpha_{k}$ are the $\mathrm{n}$ state variables (except the temperature), $\mathrm{W}_{c h}$ is the volume density of heat sources, D1 is the intrinsic dissipation, $\mathrm{r}$ symbolizes the external heat supply and $\mathrm{q}$ the heat influx vector. $\tau_{t h}$ is a characteristic constant of the local thermal looses. The subsequent assumptions to the linearization are the following: (1) the heat influx vector $\mathrm{q}$ is written $q=-k_{t h} g r a d T$ where $k_{t h}$ is the thermal conductivity coefficient assumed constant and independent of the temperature; (2) the external heat supply $\mathrm{r}$ is time independent; (3) for quasi-static processes, the convective terms of the material time derivative are negligible; (4) the thermal looses are linear [1].

The expression of $\mathrm{W}_{c h}$ is, while assuming $\mathrm{k}, \mathrm{W}_{t}, \mathrm{~W}_{c}, \operatorname{grad} \beta_{t}, \operatorname{grad} \beta_{c}, \beta_{t}$, and $\beta_{c}$ independent of the temperature:

$$
\begin{array}{r}
w_{c h}=D_{1}+(3 \lambda+2 \mu) \alpha t r \epsilon_{c} T \dot{\beta}_{c}-(3 \lambda+2 \mu) \alpha t r \epsilon_{t} T \dot{\beta}_{t}- \\
(3 \lambda+2 \mu) \alpha \beta_{c} T t r \dot{\epsilon}_{c}-(3 \lambda+2 \mu) \alpha \beta_{t} T t r \dot{\epsilon}_{t}
\end{array}
$$

with

$$
\begin{aligned}
& D_{1} \in c_{c} \dot{\beta}_{c}^{2}-\frac{1}{2} \dot{\beta}_{c}\left(\frac{1-\beta_{c}}{1-M_{c} \beta_{c}}\right)\left(2 \mu \operatorname{tr}\left[\epsilon_{c} \cdot \epsilon_{c}\right]+\lambda\left(\left\langle\operatorname{tr} \epsilon_{c}\right\rangle^{-}\right)^{2}\right)+\dot{\beta}_{c} \partial I_{-}\left(\dot{\beta}_{c}\right) \\
& \quad+c_{t} \dot{\beta}_{t}^{2}-\frac{1}{2} \dot{\beta}_{t}\left(\frac{1-\beta_{t}}{1-M_{t} \beta_{t}}\right)\left(2 \mu t r\left[\epsilon_{c} \cdot \epsilon_{t}\right]+\lambda\left(\left\langle\operatorname{tr} \epsilon_{t}\right\rangle^{+}\right)^{2}\right)+\dot{\beta}_{t} \partial I_{-}\left(\dot{\beta}_{t}\right)
\end{aligned}
$$

and for the following terms in the order: the terms of temperature - damage coupling (respectively in compression and in traction) and the terms of isentropic sources.

\subsection{Numerical simulation of a compressive test}

Six load-unloading cycles in compression piloted in deformation have been simulated. The state of stress is considered like uniform in the space, what corresponds to $\operatorname{grad} \beta_{i}=0$ and $\mathrm{k}=0 . \tau_{\text {th }}$ is determined by a proportionality ratio of the thermal conductivity of steels to those of the concretes, $\tau_{t h}=$ $10000 \mathrm{~s}$. Some experimental observations confirmed this value and leads to 
do the assumption of quasi-adiabatic tests (elevated $\tau_{t h}$ ). For $\mathrm{W}_{c}, \mathrm{M}_{c}$, and $\mathrm{c}_{c}$, the proposed values in [8] have been taken: $\mathrm{W}_{c}=0,7.10^{-2} \mathrm{MPa}, \mathrm{M}_{c}=$ $0,8, \mathrm{c}_{c}=0,5 \mathrm{MPa} . \mathrm{s}$ with besides $\mathrm{E}=25 \mathrm{GPa}, \gamma=0,2, \rho=2,2.10^{3} \mathrm{~kg} \cdot \mathrm{m}^{-3}$, $\mathrm{T}_{0}=298 \mathrm{~K}, \dot{\epsilon}_{0}=-1,3.10^{-4} \mathrm{~s}^{-1}$ and taken in the literature $\alpha=10.10^{-6} \mathrm{~K}^{-1}$, $\mathrm{C}=838 \mathrm{~J} \cdot \mathrm{kg}^{-1} \cdot \mathrm{K}^{-1}$.

Mechanical behaviour The figure 10 gives the stress-strain answer of the material and the figure 11 the evolution of the damage during the time. We recover a classic behaviour for the concrete requested in compression. To every cycle of loading the material damages it a few more (fig. 11). The consequences of the thermoelastic coupling are as well imperceptible on these curves as on the experimental curves.

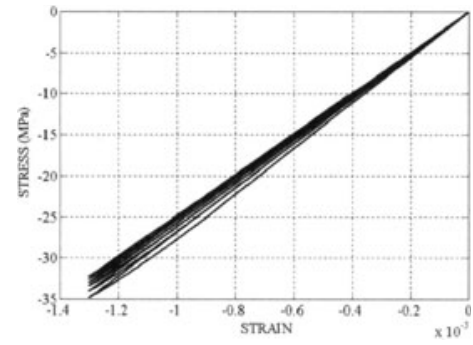

Fig. 10. Stress-strain relationship

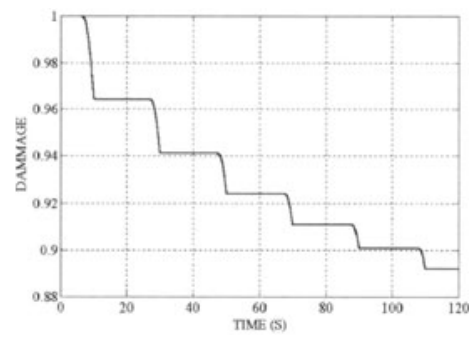

Fig. 11. Damage evolution

Thermal behaviour The thermal behaviour, resulting of the deformation and the damage of the material, is characterized by the evolution during the time of the temperature dependence, $\theta$ (fig. 16), and of the heat sources, $\mathrm{W}_{c h}$ (fig. 15), corresponding to the intrinsic dissipation, $\mathrm{D}_{1}$ (fig. 12), and to the terms of coupling temperature-damage, noted T- $\beta$ (fig. 13), and temperaturedeformation, noted T- $\epsilon$ (fig. 14). During a cycle, $\mathrm{D}_{1}$ (fig. 12) and T- $\beta$ (fig. 13) are nonzero if the damage grows ( $\beta_{c}$ decreases) to the load, the threshold of damage being exceeded. The maximal values of $\mathrm{D} 1$ and $\mathrm{T}-\beta$ decrease with the passing of the cycles because of the increase of the damage threshold. We note D1 is negligible in relation to the other heat sources terms. It is not major in the temperature variations generated by the processes of deformation and damage.

With regard to the terms of coupling, we note, for a given cycle, a "competition" between T- $\beta$ (fig. 13), that increases, with the damage and T- $\epsilon$ (fig. 14 ), that falls as and when the damage grows. The figure 15 gives, in practice, the result of this competition, D1 being negligible.

If we look at the evolution of $\theta$, under the hypothesis of quasi-adiabaticity, we note (fig. 16) the apparent superposition of two phenomena:

- the linear temperature variations, in phase with the loading-unloading 


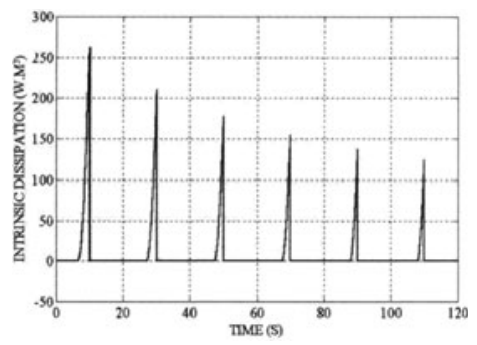

Fig. 12. $D_{1}$ evolution

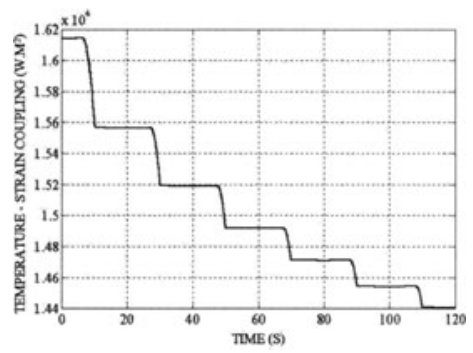

Fig. 14. T- $\epsilon$ evolution

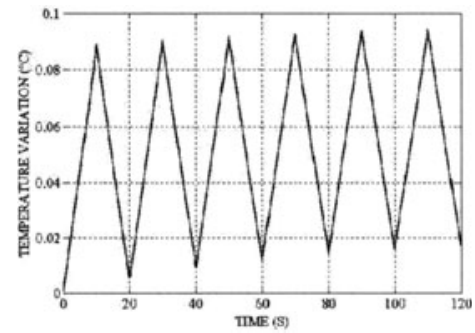

Fig. 16. Temperature evolution

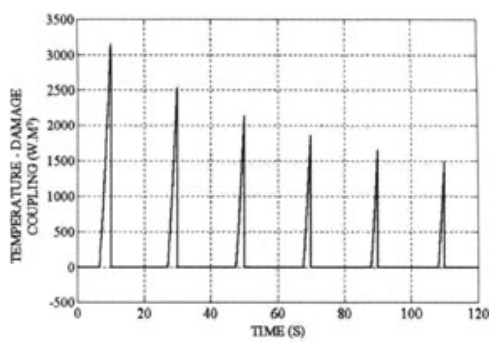

Fig. 13. T- $\beta$ evolution

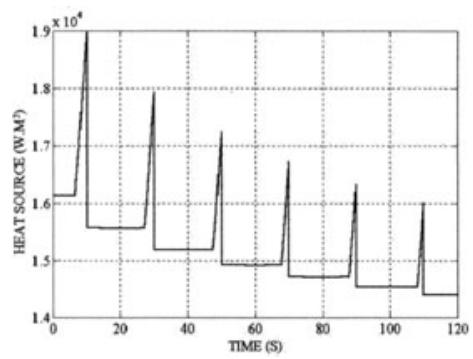

Fig. 15. Heat sources evolution

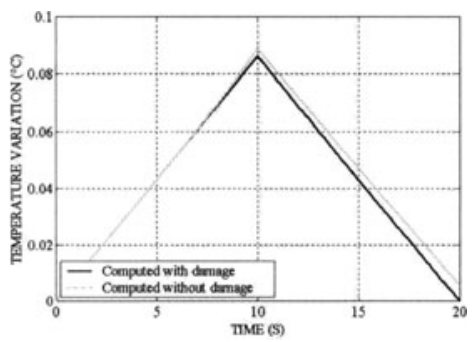

Fig. 17. For the first cycle, comparison with computed temperature

cycles, even if the damage evolves;

- a progressive warming-up of the material.

The first phenomenon results from the competition between T- $\beta$ and T- $\epsilon$. If we perform a zoom, on the first cycle, while making represent the evolution of the temperature of the material while assuming that they don't damage it, we note (fig. 17):

- a thermoelastic evolution before the threshold of damage (5 s);

- $\quad$ then an influence of T- $\beta$ and T- $\epsilon$ that offset themselves (until 7,5 s);

- $\quad$ then the major influence of T- $\beta$ lead to a temperature variation (nonlinear) more important than the one due to the only thermoelastic effect (linear) and, a fortiori, to the thermoelastic effect with damage (nonlinear).

If we add that the thermoelastic effect to the unloading of the damaged material $\left(E^{\prime}<E\right)$, cannot compensate the contribution of heat to the load, 
the non return to zero of $\theta$ at the end of the loading quite explains themselves. A progressive elevation of $\theta$ results from it at the end of every cycle (second phenomenon). We note (fig. 16) that the progressive warming-up of the material seems limited. In fact, the threshold of damage and $\beta_{c}$ have a limit depending of the maximum deformation imposed for every cycle. At the limit we would observe the effect of the thermoelastic coupling of concrete damaged.

Confrontation with the experience The results of the simulation lead to an interesting re-reading of the obtained experimental results, but not as yet beyond doubt.

Compressive cycled tests have been achieved on a plain concrete. The evolution of the temperature variation of the median axis of the sample during time is represented figure 18. In overprinting, white curve is plotted the evolution strength. The temperature variations in a point of the sample are given figure 19. These results are qualitatively very similar to those given by numerical simulation. We note the superposition of two phenomena: temperature variations in phase with the evolution of the load and a progressive warming-up of the sample. This last lets think about an effect of the damage. However, a doubt subsists on the decrease of the peak load, during the cycles. Besides, the progressive warming-up is important in relation to the results of the simulation. It is to note that the detection of a possible effect of $T-\beta$ is made again difficult by a noisy signal. In our observations, there are thermal manifestation associated to the damage of the samples certainly, but also the unavoidable phenomena of drift.

With regard to the concrete damaged by freeze/thaw cycles, for the three samples presenting different states of damage, the simulation of the compressive cycles gives a progressive warming-up more marked for the less damaged sample. The tests gave an inverse result and of intensity more marked $\left(0,3^{\circ} \mathrm{C}\right.$ at the end of test). It seems to indicate that other dissipative phenomena has been activated, on these pre-damaged sample, linked for example to contact rubbing between the lips of the microcracks, a priori of any orientations because non generated by an axial loading.

\section{Conclusions}

In spite of important experimental difficulties due to the studied material nature and to the thermal phenomenon weakness, it has been possible:

- to clearly show the thermoelastic coupling RPC's;

- $\quad$ to perform a first scanning of the temperature-damage couplings and dissipative phenomena either appearing in the damage thermoelastic behaviour of damageable concrete solicited with quasi-static way in simple compression.

Otherwise, during tests led on a RPC, the mechanical measures permitted to show precocious "multilocalisation" phenomena of the deformation. 


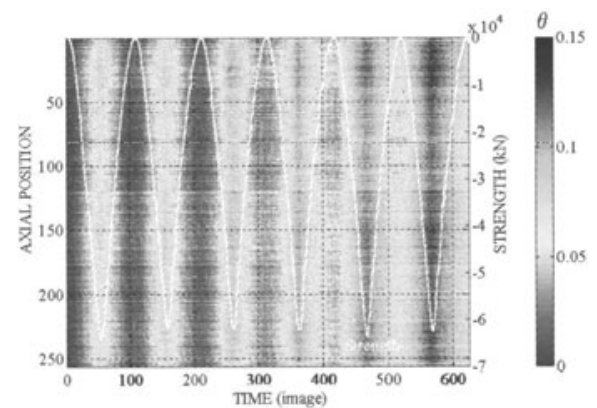

Fig. 18 Lengthwise profiles of temperature variation for RPC200 solicited in compres$\operatorname{sion}\left(\mathrm{F}_{\max }=-64 \mathrm{kN}(40 \mathrm{MPa})\right)$

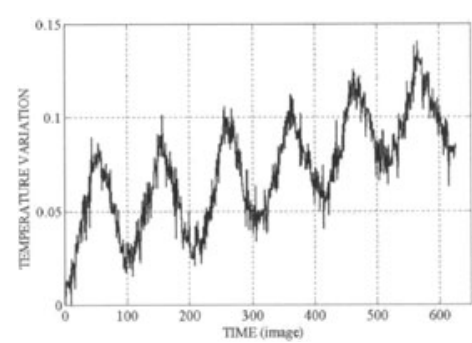

Fig. 19 Temperature variation in one point of the sample

To go farther in the analysis of the phenomena, it will agree to define the more rigorous experimental protocols, in order to be able to do the part of that reverts to the elastic deformation and the existence, the creation or to the development of micro or macrocracks.

On the point of view of the applications, the obtained results on the freeze/thaw damaged samples permit to consider interesting repercussions in the domain of the fatigue. In any case, it will be important to really master the phenomena of drift of the camera-environment set and to be able to, as for the metallic materials, to pass from the temperature maps to the heat sources.

\section{References}

1. Chrysochoos A (1987) Dissipation et blocage d'énergie lors d'un écrouissage en traction simple. Thèse de docteur d'état, Université Montpellier II

2. Chrysochoos A, Louche $H$ (2000) An infrared image processing to analyze the calorific effects accompanying strain localisation, Int. J. of Eng. Sci., Vol 38, pp 1759-1788

3. Desrues J (1983) Sur l'application de la stéréophotogrammétrie à la mesure des grandes déformations, Rev. Fr. de Mécanique, Vol 3, pp 55-63

4. Jacobsen S. (1999) Freeze/thaw cracking of $\mathrm{w} / \mathrm{c}=0.5$ prisms, Byggjorsk report 9526, Norvège

5. Lemaitre J, Chaboche JL (1985) Mécanique des matériaux solides, Dunod.

6. Luong MP (1985) Vibrothermographie infrarouge d'un béton endommagé, C. R. Acad. Sci. Paris, t 301, Série II, ${ }^{\circ} 7$, pp 459-464

7. Mazars J, Berthaud Y (1989) Une technique expérimentale appliquée au béton pour créer un endommagement diffus et mettre en évidence son caractère unilatéral, C. R. Acad. Sci. Paris, t 308, Série II, pp 579-584

8. Frémond M, Nedjar B (1996) Damage, gradient of damage and principle of virtual power, Int. J. Solids Struct., Vol 33, pp 1083-1103

9. Richard P, Cherezy M (1995) Les Bétons de Poudres Réactives, Annales de l'ITBTP Série béton $320, \mathrm{n}^{\circ} 532$, pp8 5-102

10. Wattrisse B et all (2001) Analysis of strain localization during tensile tests by digital image correlation, Experimental Mech., Vol 41, ${ }^{\circ} 1$, pp 29-39 